\title{
The effect of temperature on the mechanical properties and workability of rock salt
}

\author{
Piotr Małkowski, Łukasz Bednarek \\ Krzysztof Kotwica, Grzegorz Stopka \\ AGH University of Science and Technology, Poland
}

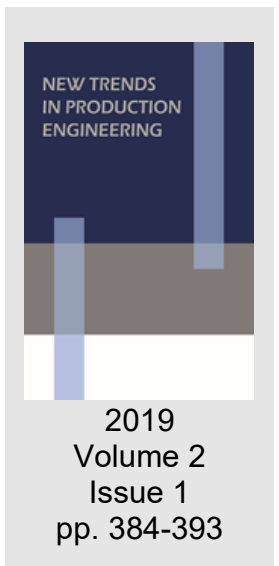

Date of submission to the Editor: 05/2019

Date of acceptance by the Editor: 08/2019

\section{INTRODUCTION}

Underground rock salt mining accounts for about a sixth of the global production of this resource. Although salt deposits are sedimentary in nature, saline sedimentation varied at different depths, often leaving salt rocks with components of carbonate rocks (mainly gypsum), as well as clay minerals, and even metamorphic rocks (Garlicki 2013, Mortazavi et al. 2017). Depending on the form of deposition, geological and mining conditions and sediment purity, salt deposits can be exploited in a number of ways (Andrusikiewicz 2008, Poborska-Młynarska 2015), using both blasting and mechanical techniques. Salt rocks usually exhibit poor or average strength, depending on mineralogical and petrographic properties (Cyran et al. 2016). In addition, their elastic-plastic behaviour in terms of strain-stress characteristics is not a typical rock behaviour, causing continuous strains as a function of time (Kolano and Flisiak 2013, Phatthaisong et al. 2018).

During salt rock excavation using mechanical techniques, the cutting heads come into contact with the rock mass, producing friction and, consequently, an increase in temperature (Powell, 1969). Hence, before solid salt rock can be cut by milling or shaping, the rock's cuttability and strength must be investigated (Andrusikiewicz 2008), including at increased temperatures.

Extensive research literature exists on mechanical alterations in salt due to changes in temperature. Sriapai et al. (2012) demonstrated that a considerable increase in temperature, reaching close to $200^{\circ} \mathrm{C}$, caused a linear decline in both the compressive and tensile strength of salt rock mass. In their paper Ostadhassan and Tamimi (2014) reported that compressive strength at similar temperatures increases logarithmically. With regard to strain parameters, researchers have found that elasticity, expressed by the Young's modulus, decreases as temperature rises. Within the range of $200^{\circ} \mathrm{C}$, it might decline by half, whereas transverse strain, expressed by Poisson's ratio, usually increases by more than 10 percent (Iverson et al. 2012, Sartkaew \& Fuenkajorn 2013, Phatthaisong et al. 2018). 
Since the rise in temperature of the rock mass due to friction by cutter heads is short-lived and localized, no such significant increases in temperature are recorded. This paper presents the results of laboratory tests of geomechanical and cuttability properties of rock salt. The tests were performed on samples cut from a lump of rock salt and heated to about $50^{\circ} \mathrm{C}$ and $80^{\circ} \mathrm{C}$. An analysis was performed of the results of compressive, tensile and induced-shear strengths, and of Young's modulus, Poisson's ratio, the cuttability index and the side chipping angle.

\section{TESTS OF MECHANICAL PROPERTIES}

The tests were performed on Miocene salt from a Carpathian region (Garlicki 2013). The lumps of salt sampled for testing varied in colour from white to greycoloured. The brightest (white) variety was the purest. It was nearly monomineralic. The chemical and mineralogical analyses showed that this variety was 99.7 percent halite. Other identified minerals included anhydrite and potassium and iron aluminosilicates - most likely clay minerals. The darkest varieties were 98.17 percent halite. Other identified minerals in these salt samples included anhydrite, whose very small portion transformed into gypsum. To determine compressive, tensile and shear strengths, cut-out cube samples with a side length of $50 \mathrm{~mm}$ were used. Elastic parameters testing (Young's modulus and Poisson's ratio) involved samples with a slenderness of 1.5. This is consistent with the guidelines of the International Society for Rock Mechanics (ISRM), although for strain tests of rocks, it is recommended to use samples with a slenderness of 2-2.5. Due to the atypical elastic-plastic behaviour of the salt samples under load, the values obtained should not differ significantly from those provided by tests on more slender samples. Four to eight determinations per parameter were made for each sample at pre-defined temperatures of $23^{\circ} \mathrm{C}$, $50^{\circ} \mathrm{C}$, and $80^{\circ} \mathrm{C}$.

Compressive strength was determined according to the PN-G 04303:1997 standard. The rate of loading, relative to the transverse cross-section of the sample, depended on the rock strength. In the case under analysis, the rate was $0.4 \mathrm{kN} / \mathrm{s}$ (approx. $0.12 \mathrm{MPa} / \mathrm{s}$ ). The tensile strength was determined using the transverse compression method (the so-called Brazilian test) according to the PN-G 04302:1997 standard. The test involved splitting the sample by applying compressive strength distributed uniformly along the side of the sample and perpendicular to the layers with the use of a specially designed mould (Fig. 1). The rate of loading relative to the sample's transverse cross-section was 0.05 $\mathrm{kN} / \mathrm{s}$. Shear strength was tested using a method proposed by ISRM in 1975 involving an induced shear angle of $45^{\circ}$ (Fig. 2). This involved compressing the sample in special moulds with one washer that adjusted the concentric alignment of the moulds to ensure equal shear area.

The longitudinal strain modulus (Young's modulus) and transverse strain modulus (Poisson's ratio) were determined in line with ISRM's guidelines (Ulusay \& Hudson 2007) in two ways: as a value within the complete elastic region understood as the linear relationship between stress and longitudinal 
strain (Young's modulus), and as a secant value based on $0 R_{c}$ and $0,5 R_{c}$ relative to strain increase between these stress values (deformation modulus). During the tests, the outer temperature, as well as the inner temperature - after failure - were being monitored continuously with a thermographic camera.

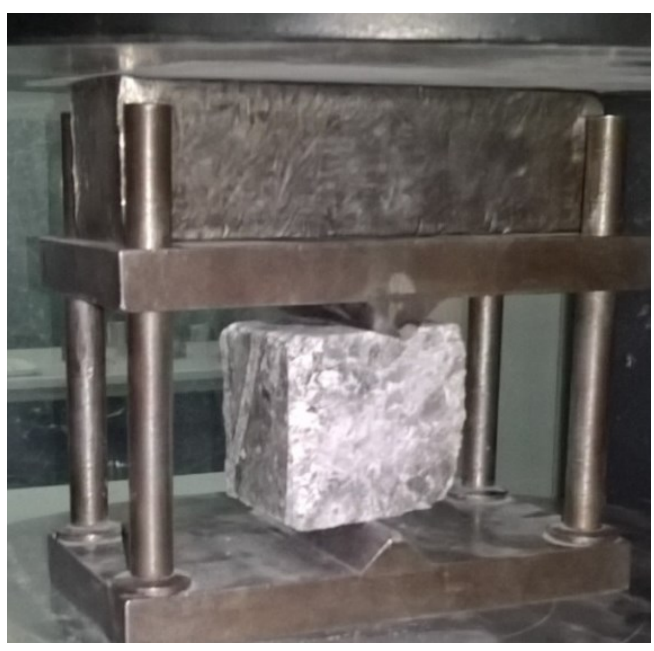

Fig. 1 Sample subjected to the Brazilian tensile test

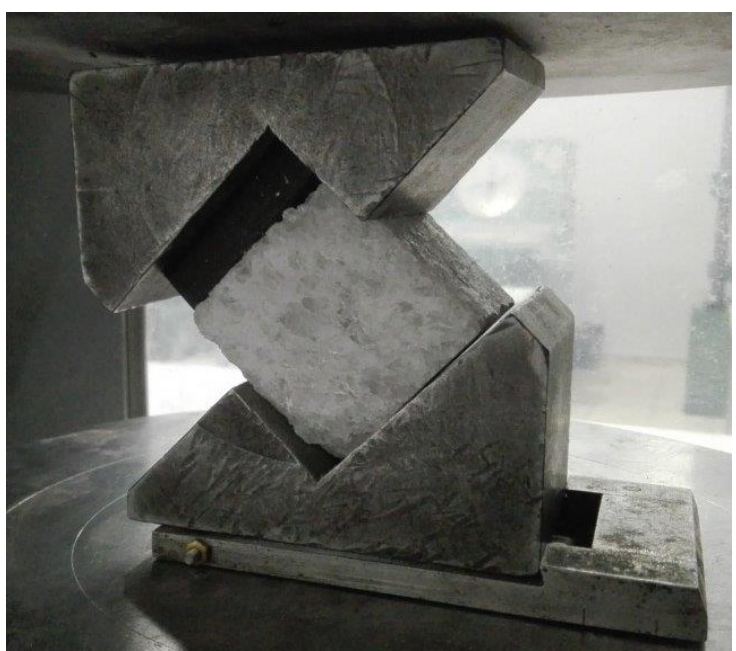

Fig. 2 Sample during a induced-shear test

Table 1 summarises the average test results. It is evident that both compressive and tensile strength values increased along with temperature, from $24.8 \mathrm{MPa}$ to 28.2 MPa, and from 1.67 MPa to 2.14 MPa, respectively.

Table 1 Average strength and strain parameters

\begin{tabular}{|c|c|c|c|c|}
\hline \multicolumn{2}{|c|}{ Temperature } & $20^{\circ} \mathrm{C}$ & $50^{\circ} \mathrm{C}$ & $80^{\circ} \mathrm{C}$ \\
\hline \multicolumn{2}{|l|}{ Bulkdensity $\rho\left[\mathrm{kg} / \mathrm{m}^{3}\right]$} & 2096.65 & 2109.24 & 2091.11 \\
\hline \multirow{3}{*}{ Compressivestrenght } & $\sigma_{\mathrm{c}}[\mathrm{MPa}]$ & 24.86 & 24.08 & 28.20 \\
\hline & Real outerav temp. & 23.05 & 50.25 & 79.16 \\
\hline & number of samples & 8 & 8 & 8 \\
\hline \multirow{4}{*}{ Tensilestrength } & $\sigma_{t}[\mathrm{MPa}]$ & 1.67 & 1.98 & 2.14 \\
\hline & Real outerav temp. & 23.08 & 49.68 & 75.91 \\
\hline & Real innerav temp. & 23.08 & 49.57 & 76.27 \\
\hline & number of samples & 5 & 4 & 4 \\
\hline \multirow{3}{*}{ Shearstrength $-45^{\circ}$} & $\sigma_{\mathrm{s}}[\mathrm{MPa}]$ & 22.12 & 21.03 & 19.07 \\
\hline & Real outerav temp. & 23.15 & 48.75 & 71.81 \\
\hline & number of samples & 5 & 7 & 4 \\
\hline \multirow{5}{*}{$\begin{array}{l}\text { Young modulus } \\
\text { and Poisson ratio }\end{array}$} & $\mathrm{E}_{\mathrm{av}}[\mathrm{GPa}]$ & 1.50 & 1.21 & 1.08 \\
\hline & $V_{a v}[-]$ & 0.10 & 0.17 & 0.20 \\
\hline & $E_{\mathrm{sec}}[\mathrm{GPa}]$ & 1.30 & 1.07 & 1.02 \\
\hline & $v_{\text {sec }}[-]$ & 0.45 & 0.29 & 0.33 \\
\hline & number of samples & 6 & 8 & 8 \\
\hline
\end{tabular}

The samples heated to about $80^{\circ} \mathrm{C}$ showed a 13.5 percent increase in compressive strength compared to samples at room temperature. The tensile 
strength of the samples heated to $80^{\circ} \mathrm{C}$ increased by an average of 28.1 percent. A reverse trend was observed for shear strength. As temperature increased, shear strength decreased from 22.1 MPa to 19.1 MPa. This can be considered an advantage especially for mechanical salt rock cutting. It should be noted, however, that the test methodology provided an induced shear angle of $45^{\circ}$, while the actual internal friction angle for salt is usually about 28-30 (Kolanoand Flisiak 2013), although it can exceed $50^{\circ}$ as well (Ostadhassanand Tamimi 2014).

The strain parameters - the Young's modulus and Poisson's ratio - were calculated as both average and secant values. This was due to the elasticplastic behaviour of salt, for which the elastic region is small - below 50 percent of the critical stress value. The test results showed that linear strain increased with temperature (the modulus decreased), and that transverse strain increased with temperature as well (the ratio increased). Because plastic strains occurred at 50 percent of critical stress, it was difficult to interpret the obtained transverse strain $v_{\text {sec. }}$ Generally, the results are in agreement with the values obtained by Cyran (Cyran et al. 2016 - Table 2)

Table 2 Average strength and strain parameters for Miocene salt varieties according to Cyran et al. (2016) and authors' tests

\begin{tabular}{|c|c|c|c|c|}
\hline Deposit & Petrological description & $\begin{array}{l}\text { Uniaxial compression } \\
\text { strength } \sigma_{c}[\mathrm{MPa}]\end{array}$ & $\begin{array}{c}\text { Young's } \\
\text { modulus } \\
E \text { [GPa] }\end{array}$ & $\begin{array}{l}\text { Poisson's } \\
\text { ratio }\end{array}$ \\
\hline \multirow{4}{*}{$A$} & $\begin{array}{l}\text { medium-grade salt, grey and } \\
\text { white }\end{array}$ & 29.69 & 1.31 & 0.17 \\
\hline & medium-grade salt, grey & 25,93 & 2.29 & 0.23 \\
\hline & crystal salt & 23.33 & 1.63 & 0.22 \\
\hline & $\begin{array}{l}\text { fine-grade salt, grey and } \\
\text { white }\end{array}$ & 26.22 & 1.81 & 0.35 \\
\hline \multirow{4}{*}{$\mathrm{Be}$} & $\begin{array}{l}\text { medium-grade salt, grey and } \\
\text { white }\end{array}$ & 37.96 & 2.02 & 0.15 \\
\hline & $\begin{array}{l}\text { grey salt, medium- to coarse- } \\
\text { grade }\end{array}$ & 33.57 & 1,14 & 0.10 \\
\hline & fine-grade salt, grey & 32.49 & 0.83 & 0.30 \\
\hline & $\begin{array}{l}\text { banded salt, fine- to medium- } \\
\text { grade }\end{array}$ & 36.36 & 2.85 & 0.10 \\
\hline C & $\begin{array}{l}\text { coarse-grade salt, white, } \\
\text { light grey and grey }\end{array}$ & 24.86 & 1.50 & 0.10 \\
\hline
\end{tabular}

An analysis of the dispersion of compressive and tensile strength results (Fig. 3 and 5 ) indicated that the samples at room temperature exhibited much greater strength variability than the samples heated to $50^{\circ} \mathrm{C}$ and $80^{\circ} \mathrm{C}$. During prolonged determinations of compressive strength, which involved recording transverse and longitudinal strains to determine the moduli, the samples were found to release heat rapidly, and temperature decreased at a high rate as well. The samples heated to $50^{\circ} \mathrm{C}$ cooled to a maximum surface temperature of $38^{\circ} \mathrm{C}$, while those heated to $80^{\circ} \mathrm{C}$ changed their temperature locally to $46^{\circ} \mathrm{C}$. It should be added, however, that the such sharp drops in sample temperatures occurred only in several cases. In most cases temperatures decreased by a dozen-odd degrees. 


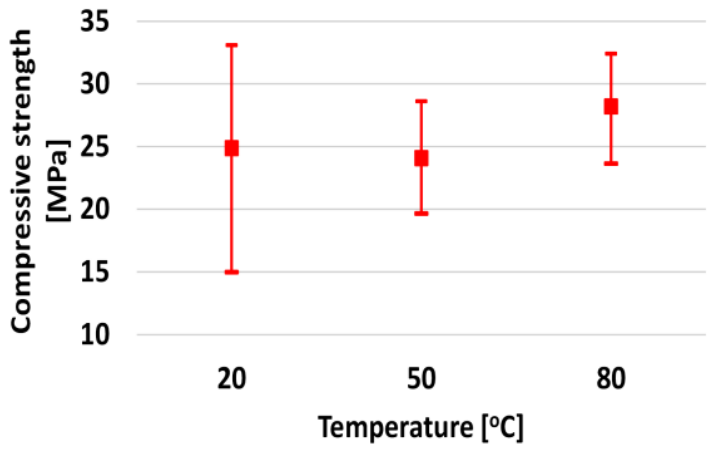

Fig. 3 Compressive strength range

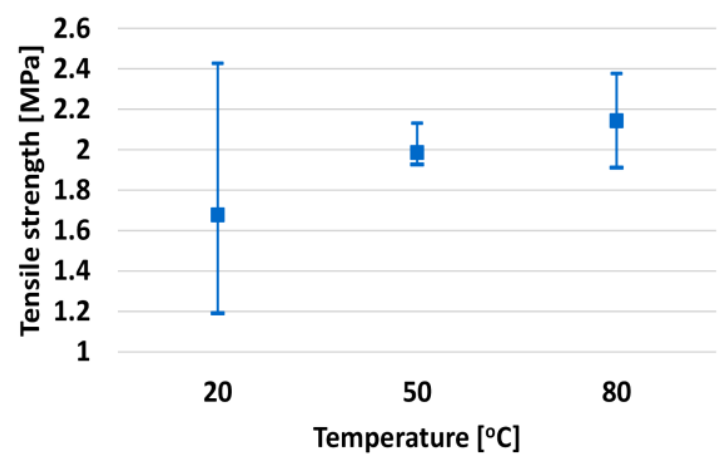

Fig. 5 Tensile strength range

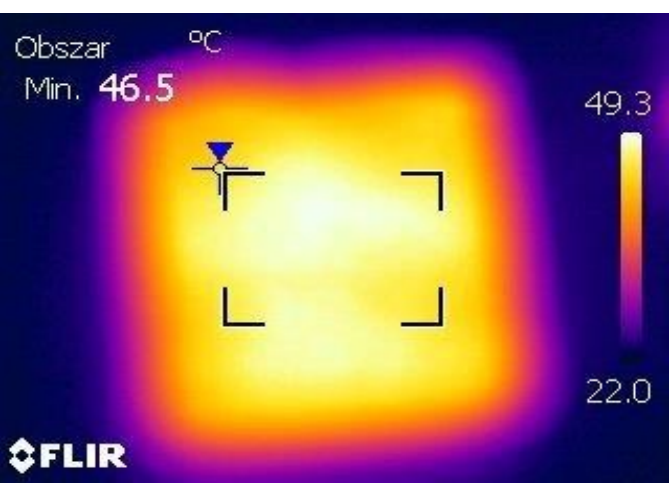

Fig. 4 Sample temperature after the compressive strength test (heated to $50^{\circ}$ )

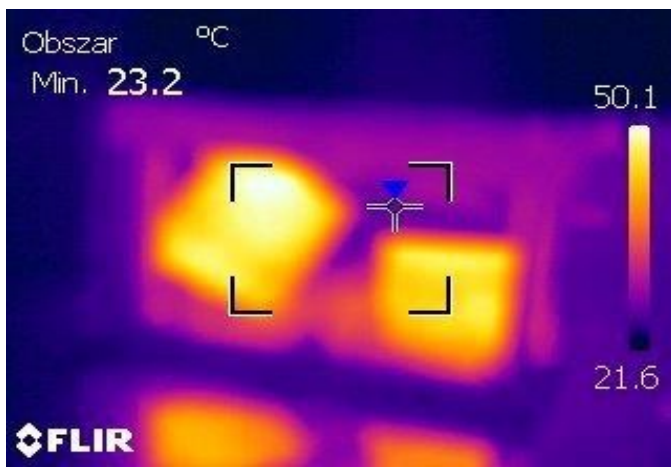

Fig. 6 Sample temperature after the tensile strength test (heated to $50^{\circ}$ )

Figure 6 shows two halves of a sample split after the Brazilian tensile test in which the temperature was still about $50^{\circ} \mathrm{C}$.

The obtained average shear strength values decreased proportionally to rising temperatures (Fig. 7). In a sense, shear strength is a parameter the provides the closest reflection of rock behaviour during mechanical salt rock mining.

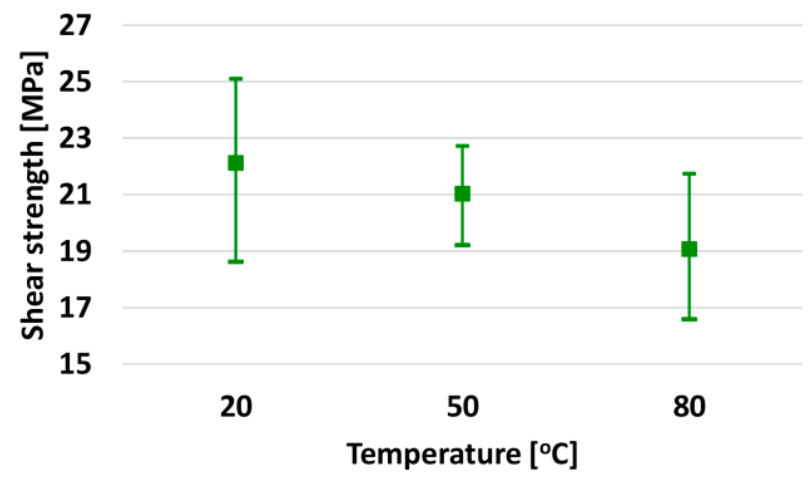

Fig. 7 Shear strength range

The cutting operation by the knives of road headers can be compared with rockmass shear. Therefore, shear strength can be considered a parameter that describes the process of rock pieces separationt. Figure 8 shows the relationship between shear strength and displacement at a pre-defined angle of $45^{\circ}$. The tests showed that salt was so plastic as to require a displacement of nearly $6 \mathrm{~mm}$ to reach critical shear strength. 


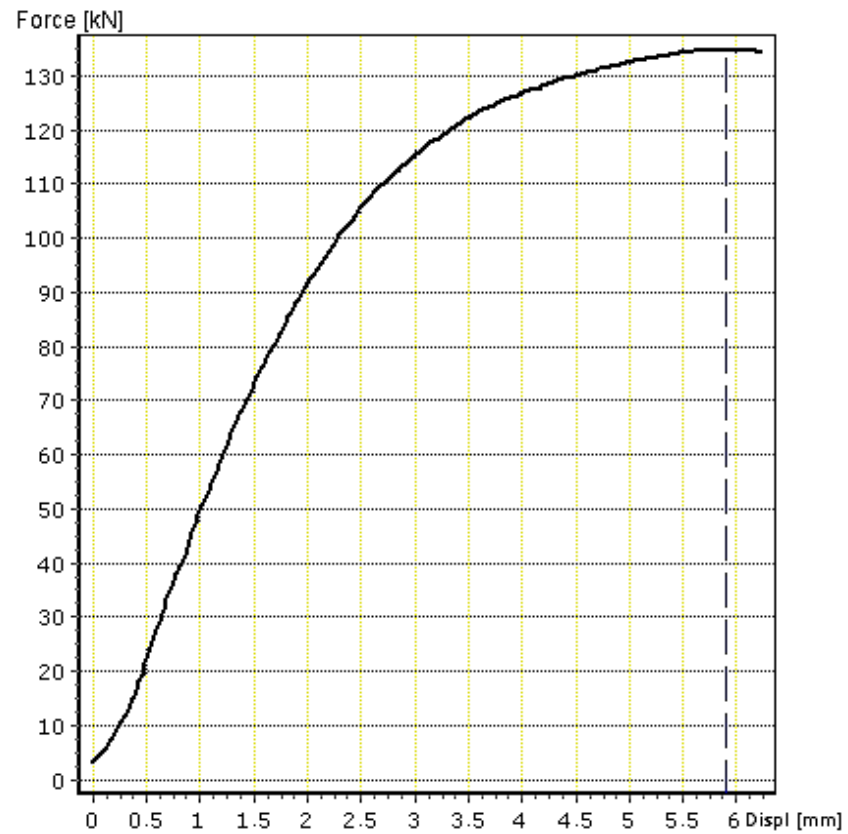

Fig. 8 A diagram from the testing machine during the shear test

At high temperatures, salt elasticity expressed as Young's modulus (Fig. 9) decreased as well, which is consistent with literature reports.

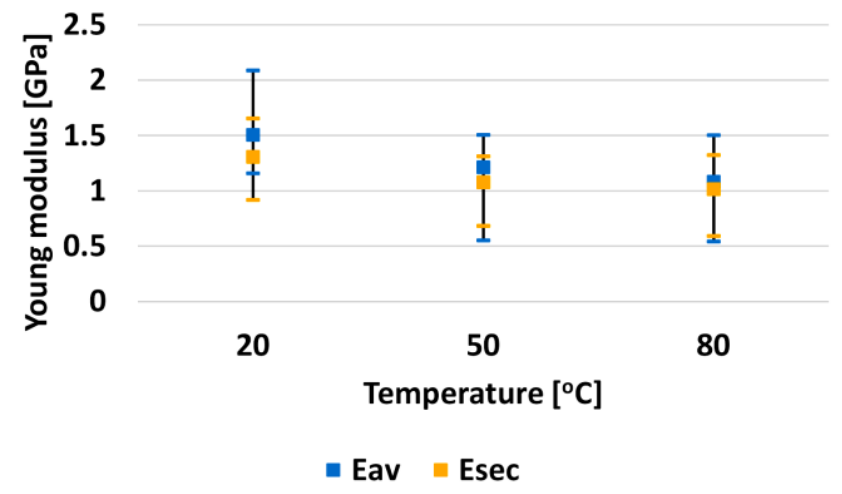

Fig. 9 Young's modulus range

With regard to Poisson's ratio (Fig. 10), determined within a very narrow range (0-0.5), one value can often disturb a certain trend. Thus, it is difficult to state whether temperature has an effect on salt rock strain behaviour.

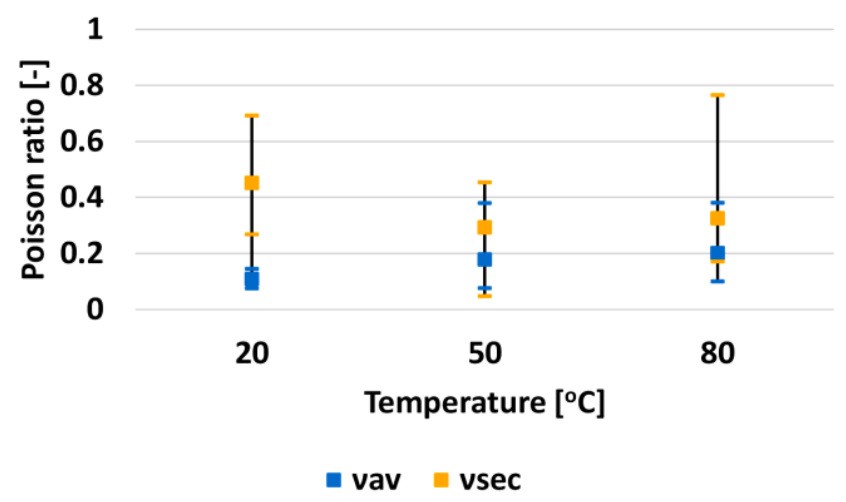

Fig. 10 Poisson's ratio range 


\section{CUTTABILITY INDEX TEST}

The laboratory test to determine the cuttability index $A$ and the side chipping angle $\psi$ involved making open cuts in the rock samples using a standard test cutter. The cutting depth was predefined. The tests were designed to measure the components of the cutting resistance ( $P s$ - cutting force, $P d$ - contact force, $P b$ - lateral force). Subsequently, the cuts are measured to determine the actual cutting depth $g_{s}$ and cutting width $b_{s}$. The resulting values $P s, P d, P b, g_{s}$ and $b_{s}$ could then be used to determine the cuttability index $A$ (the ratio of the resultant cuttability resistance and the cutting depth) and the side chipping angle $\psi$ (the ratio of the opening-cut width difference arctangent and the double cutting depth).

For this purpose, a test facility was used that recorded the components of the rock sample's cutting resistance. Figure 11 illustrates this facility.

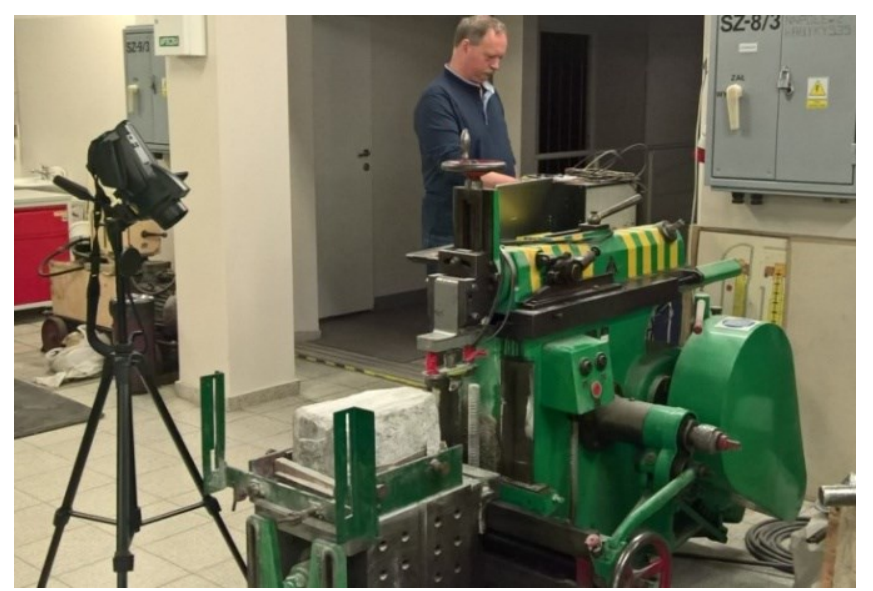

Fig. 11 Shaper-based cutting resistance test stand with a strain-gauge head

The cutting resistance test facility consists of a horizontal shaper, a strain-gauge head (test cutter handle) fitted with a standard test radial cutter, and a rocksample specimen holder on the shaper table. The signals from the gauge head are sent through conductors via the strain-gauge amplifier to the measurement computer for recording and further processing and analysis. The cutting tests were performed for the temperatures of $22^{\circ} \mathrm{C}$ and about $50^{\circ} \mathrm{C}$ and $80^{\circ} \mathrm{C}$. The measurements were taken on cuts with a depth of $g_{s}=5 \mathrm{~mm}$ at the cutting speed vs of about $1 \mathrm{~m} / \mathrm{s}$. Each consecutive cut was made at a scale interval ts of at least $30 \mathrm{~mm}$. Also, thermographic images were captured during the cutting tests. Each cut sample was heated to about $55^{\circ} \mathrm{C}$ in an oven and placed in the shaper hand. Once the sample's surface was even again, the procedure was repeated with a cutting depth of $5 \mathrm{~mm}$. After cutting, signs of cracking were noticed in the midsection of the sample. Next, after the sample was heated to about $83^{\circ} \mathrm{C}$ and its surface was again evened, new cuts were made with a cutting depth of $5 \mathrm{~mm}$. Figure 12 shows the sample surface with these cuts. In the sample midsection, crack propagation can be seen leading down to the bottom surface of the sample. 


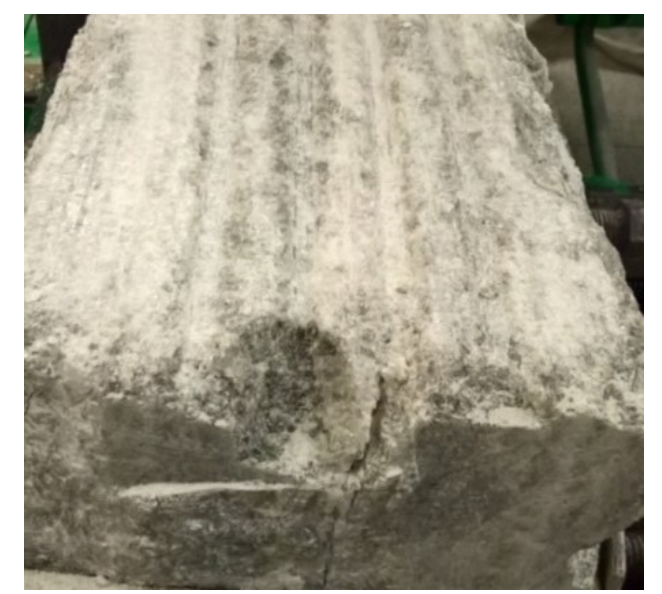

Fig. 12 Sample with cuts made at about $75^{\circ} \mathrm{C}$

A comparison of the cut temperatures (Figures 13 and 14) showed that at $22^{\circ} \mathrm{C}$ the cut surface temperature rose to about $27.5^{\circ} \mathrm{C}$ along its entire length, and at $55^{\circ} \mathrm{C}$, the temperature rose only in the end section of the cut - by $4^{\circ} \mathrm{C}$.

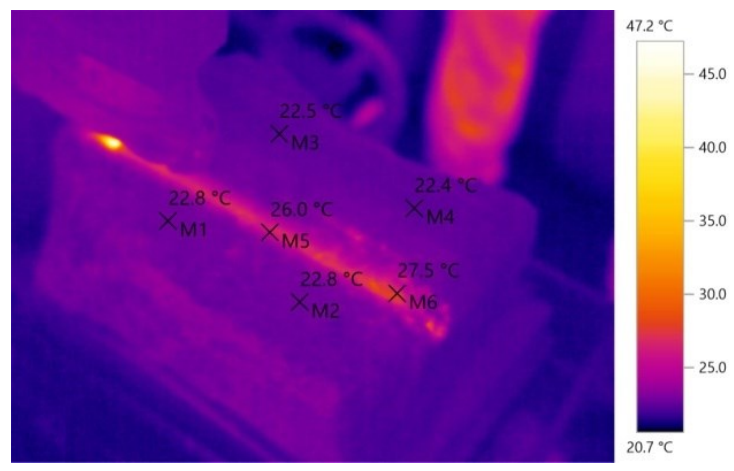

Fig. $13 \mathrm{~A}$ thermogram of a sample being cut at $20^{\circ} \mathrm{C}$

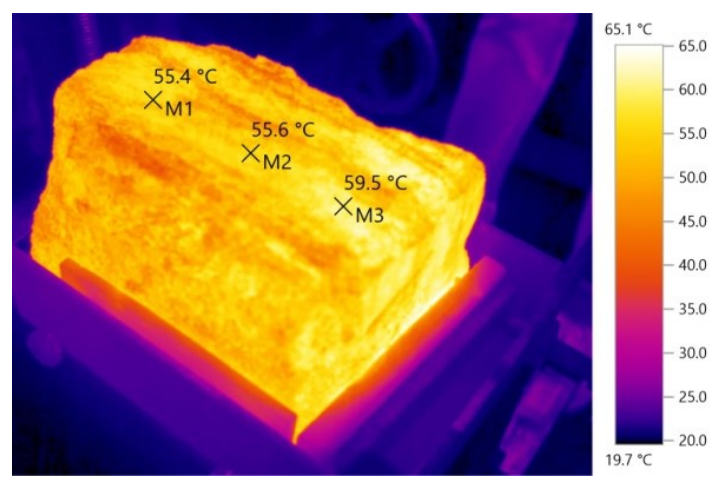

Fig. $14 \mathrm{~A}$ thermogram of a sample being cut at $57^{\circ} \mathrm{C}$

An analysis of the results for the cuttability index $A$ and the side chipping angle $\psi$ indicated that the salt behaviour was similar to that observed in the shear strength measurements. As the sample temperature rose, the cuttability index $A$ and the side chipping angle $\psi$ decreased markedly. After excluding outliers (for measurements at $20^{\circ} \mathrm{C}$, this was due to a big piece of salt chipping off from the lateral surface, and for measurements at 55 and $77^{\circ} \mathrm{C}$, due to salt-sample cracking), the average values of the cuttability index $A$ and side chipping angle $\psi$ were:

- $20^{\circ} \mathrm{C}-\mathrm{A}=2.192 \mathrm{kN} / \mathrm{cm}, \psi=55.8^{\circ}$

- $55^{\circ} \mathrm{C}-\mathrm{A}=1.742 \mathrm{kN} / \mathrm{cm}, \psi=51.2^{\circ}$

- $77^{\circ} \mathrm{C}-\mathrm{A}=1.653 \mathrm{kN} / \mathrm{cm}, \psi=48.7^{\circ}$.

Data on the cuttability of the studied material, depending on the cuttability index $A$ and the side chipping angle $\psi$ (based on the coal cuttability index provided by CMG KOMAG Gliwice) indicate that at room temperature the salt sample can be classified as a medium-cuttable material. When heated to $50^{\circ} \mathrm{C}$, it becomes a highly workable material. However, the side chipping angle $\psi$ decreases instead of growing. 


\section{CONCLUSION}

The tests and analysis of results have led to the following conclusions:

- The compressive and tensile strength of salt when heated from room temperature to $80^{\circ} \mathrm{C}$ can increase by as much as 28 percent. This is a considerable change in strength properties within a relatively small range of temperatures.

- The mechanical rock excavation process can be compared to the mechanical parameter of shear strength. In the case studied, rising temperatures caused this strength to decrease. Despite being heated, however, the samples continued to exhibit considerable plasticity. Critical shear strength could be reached only after displacing two surfaces of the sample by several millimetres at a predefined angle of $45^{\circ}$.

- In the salt sample heated to $80^{\circ} \mathrm{C}$, the cuttability index $A$ decreased by almost 25 percent, and the side chipping angle $\psi$ by 13 percent.

- The elasticity of the tested salt, expressed by the Young's modulus, was low at about $1.5 \mathrm{GPa}$, and the modulus decreased as the sample was heated. As temperature rose, transverse strain had almost doubled. This suggests that salt brittleness increased even though the salt sample's temperature rose by only about $60^{\circ} \mathrm{C}$.

\section{REFERENCES}

Andrusikiewicz, W. (2008). Możliwość zmiany sposobu urabiania soli kamiennej w KS Kłodawa. Gospodarka Surowcami Mineralnymi, 24(3/2), pp. 173-183.

Cyran, K., Toboła, K. and Kamiński, P. (2016). Wpływ cech petrologicznych na właściwości mechaniczne soli kamiennej z LGOM. Biuletyn Państwowego Instytutu Geologicznego, 466, pp. 51-64, DOI: 10.5604/01.3001.0009.4572.

Garlicki, A. (2013). Salt mines in the world. In: Wieliczka Salt Mine - An Underground Treasure, A. Nowakowski ed., Universitat, pp. 15-34.

Iverson, B. D., Broome, S. T., Kruizenga, A. M. and Cordaro J. G. (2012). Thermal and mechanical properties of nitrate thermal storagesalts in the solid-phase. Solar Energy, 86, pp. 2897-2911.

Kolano, M., Flisiak D. (2013). Comparison of geo-mechanical properties of white rock salt and pink rock salt in Kłodawa salt diapir. Studia Geotechnica et Mechanica, XXXV(1), DOI: 10.2478/sgem-2013-0010.

Mortazavi, M., Heuss-Assbichler, S. and Shahri M. (2017). Hydrothermal systems in the salt domes of south Iran. Procedia Earth and Planetary Science, 17, pp. 913916.

Ostadhassan, M., Tamimi N. (2014). Mechanical behavior of salt rock atelevated temperature. The $48^{\text {th }}$ US Rock Mechanics Conference, Minneapolis, USA, ARMA 14-7122.

Pforr, H. (1975). Wytyczne Międzynarodowego Biura Mechaniki Górotworu do określania parametrów geomechanicznych skał i górotworu. Gliwice (unpublished - in Polish).

Phatthaisong, K., Sartkaew, S., Fuenkajorn, K. (2018). Effects of loadingrate and temperature on strength and deformability of Maha Sarakham salt. Songklanakarin J. Sci. Technol., 40(2), pp. 359-366.

Poborska-Młynarska, K. (2015). Współczesne techniki eksploatacji soli kamiennej w kopalniach podziemnych. Przegląd Górniczy, 12, pp. 140-146.

Powell, F. (1969). Ignition of Gases and Vapors. Ind. Engr. Chem., Vol. 61, no. 12, pp. 29-37. 
Sartkaew, S., Fuenkajorn K. (2013). Effects of stress rate on uniaxial compressives trength of rock salt under $0-100^{\circ} \mathrm{C}$. The $11^{\text {th }}$ International Conference on Mining, Materials and Petroleum Engineering. November 11-13 2013, Chiang Mai, Thailand, pp. 13-20.

Sriapai, T., Walsri, Ch., Fuenkajorn, K. (2012). Effect of temperature on compressive and tensil estrengths of salt. Science Asia, 38, pp. 166-174.

Ulusay, R. \& Hudson, J.A. ed. (2007). The Complete ISRM Suggested Methods for Rock Characterization. Testing and Monitoring: 1974-2006. ISRM Turkish National Group, Ankara.

\begin{abstract}
.
Underground salt mining accounts for about 16 percent of the total salt production worldwide. When excavating salt rock, the cutters of the road header come into contact with the rock. This produces friction and, consequently, a rise in temperature. Generally, as temperature increases, salt gradually loses its plasticity. The extent of these alterations depends on the presence of other minerals in the rock. This paper presents the results of laboratory tests on regularly shaped samples of salt. An analysis was performed of the results of compressive, tensile and induced-shear strength, and of Young's modulus, Poisson's ratio, cuttability index and side chipping angle. The testing was conducted on samples with a temperature of about $20^{\circ} \mathrm{C}$ and samples heated to $50^{\circ} \mathrm{C}$ and $80^{\circ} \mathrm{C}$. The tests showed that as temperature increased, so did compressive and tensile strength, and longitudinal and transverse strain of salt. The temperature increase caused, however, a decrease in shear strength. The cuttability index and the side chipping angle also decreased when the heated samples were being cut. The percentage changes in the parameters within the 60-degree temperature range were as high as several dozen percent.
\end{abstract}

Keywords: rock salt testing, mechanical salt parameters, salt cutability, temperature change of salt 